\title{
Impacts of an integrated multi-trophic aquaculture system on benthic nutrient fluxes: a case study in Sanggou Bay, China
}

\author{
Zhiming Ning ${ }^{1}$, Sumei Liu ${ }^{1,2, *}$, Guoling Zhang ${ }^{1}$, Xiaoyan Ning ${ }^{1}$, Ruihuan Li $^{1,5}$, \\ Zengjie Jiang ${ }^{3}$, Jianguang Fang ${ }^{3}$, Jing Zhang ${ }^{4}$ \\ ${ }^{1}$ Key Laboratory of Marine Chemistry Theory and Technology MOE, Ocean University of China/ \\ Qingdao Collaborative Innovation Center of Marine Science and Technology, Qingdao 266100, PR China \\ ${ }^{2}$ Laboratory of Marine Ecology and Environmental Science, Qingdao National Laboratory for Marine Science \\ and Technology, Qingdao 266100, PR China \\ ${ }^{3}$ Key Laboratory of Sustainable Utilization of Marine Fisheries Resources, Ministry of Agriculture, \\ Yellow Sea Fisheries Research Institute, Chinese Academy of Fishery Sciences, Qingdao 266071, PR China \\ ${ }^{4}$ State Key Laboratory of Estuarine and Coastal Research, East China Normal University, Shanghai 200062, PR China \\ ${ }^{5}$ Present address: State Key Laboratory of Tropical Oceanography, South China Sea Institute of Oceanology, \\ Chinese Academy of Sciences, Guangzhou 510301, PR China
}

\begin{abstract}
Benthic nutrient fluxes in an integrated multi-trophic aquaculture (IMTA) baySanggou Bay, China - were measured in June and September 2012. The benthic nutrient fluxes and total organic carbon (TOC) of sediment in this IMTA system were significantly lower than in monoculture bays. This was due to the efficient recycling of organic matter in the IMTA system, as revealed by historical data of annual production, dissolved inorganic nitrogen (DIN) concentration in seawater and TOC in sediment. Benthic nutrient fluxes in the IMTA system were mainly controlled by seawater temperature, dissolved oxygen (DO) and nutrient concentrations, which were strongly related to aquaculture activities. In June, the early growth phase of cultured finfish and bivalves contributed little to biodeposition, and benthic nutrient fluxes tended to be from the sediment to the seawater and contributed to algal growth. In September, the active growth of finfish and bivalves resulted in high concentrations of nutrients in the seawater and TOC in the sediment; $64 \%$ of the nitrogen and $25 \%$ of the phosphorus metabolized by bivalves were transferred from the seawater to the sediment.
\end{abstract}

KEY WORDS: Benthic nutrient fluxes $\cdot$ Pore water $\cdot$ Core incubation $\cdot$ Integrated multi-trophic aquaculture $\cdot$ IMTA $\cdot$ Sanggou Bay

\section{INTRODUCTION}

World fisheries and aquaculture production has grown rapidly to meet increasing market demand (FAO 2012), and consequently ecosystem biodiversity, productivity and health of marine organisms have been negatively affected. An approach termed 'integrated multi-trophic aquaculture' (IMTA, Fig. 1) was proposed to mitigate these environmental pressures (Tang \& Fang 2012) and was implemented in shallow

\footnotetext{
*Corresponding author: sumeiliu@ouc.edu.cn
}

coastal bays including the Bay of Fundy (Canada), and Sanggou Bay and Ailian Bay (China) (Troell et al. 2009, Tang \& Fang 2012, Chopin 2013). In terms of production and economic performance, the clear benefits of employing IMTA as opposed to monoculture have been reported (Tang \& Fang 2012). However, no sufficient evaluation of the environmental effects of IMTA in comparison to monoculture has been made. Despite the increasing recognition that nutrients are fundamental to the food web in aquaculture eco-

() The authors 2016. Open Access under Creative Commons by Attribution Licence. Use, distribution and reproduction are unrestricted. Authors and original publication must be credited. 


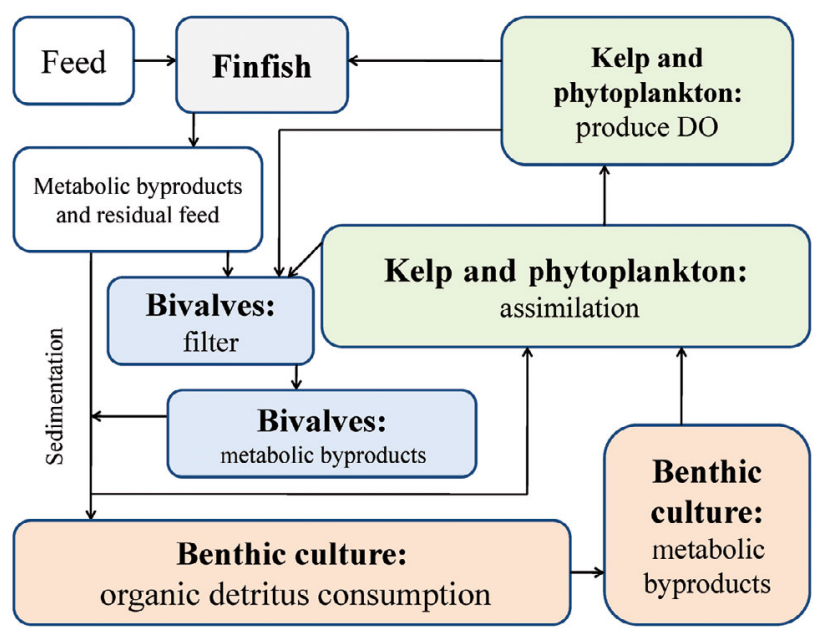

Fig. 1. Diagrammatic representation of the integrated multitrophic aquaculture (IMTA) system in Sanggou Bay, China, modified from Tang \& Fang (2012). DO: dissolved oxygen

systems, information about the internal nutrient cycles in IMTA systems is still unavailable (Sequeira et al. 2008, Troell et al. 2009, Tang \& Fang 2012, Chopin 2013). Benthic nutrient regeneration is a significant source of nutrients for primary production in coastal waters (Liu et al. 2003, Sundbäck et al. 2003, Lee et al. 2011). Conversely, nutrients can be stored in the sediments via burial and denitrification (Aller et al. 1985, Song et al. 2013). Hence, an accurate account of nutrient fluxes across the sediment-water interface and the roles of these processes in IMTA systems are of significance to fisheries management.
Many studies have focused on seawater conditions, nutrient uptake efficiency of bivalves, and aquaculture capacity and impacts in Sanggou Bay (Nunes et al. 2003, Mao et al. 2006, Zhang et al. 2009, Lu et al. 2015), but knowledge of the benthic nutrient fluxes in the IMTA system and comparisons of the environmental impacts of IMTA and monoculture are insufficient (Zhang et al. 2006). The aim of this study was to investigate the impacts of aquaculture on benthic nutrient fluxes in the IMTA system, and sedimentary mineralization processes based on nutrient data in pore water, to evaluate the environmental effects of IMTA with respect to benthic nutrient fluxes.

\section{MATERIALS AND METHODS}

\section{Study area}

Sanggou Bay is a typical IMTA bay located on the western margin of the Yellow Sea (Fig. 2). It is semienclosed, with a mean depth of $7.5 \mathrm{~m}$, a total area of $144 \mathrm{~km}^{2}$, and a mean salinity of 31 (Zhang et al. 2009). Kelp is cultivated mainly outside the mouth of the bay; bivalves are near the end of the bay. Polyculture of kelp and bivalves occurs centrally between the former 2, and sea cage culture of finfish occurs along the southwest coast. The annual production of kelp, finfish, scallop and oyster were 84500,535 , 15000 and $60000 \mathrm{t}$ in 2012 (the statistical data from the Rongcheng Fishery Technology Extension Sta-
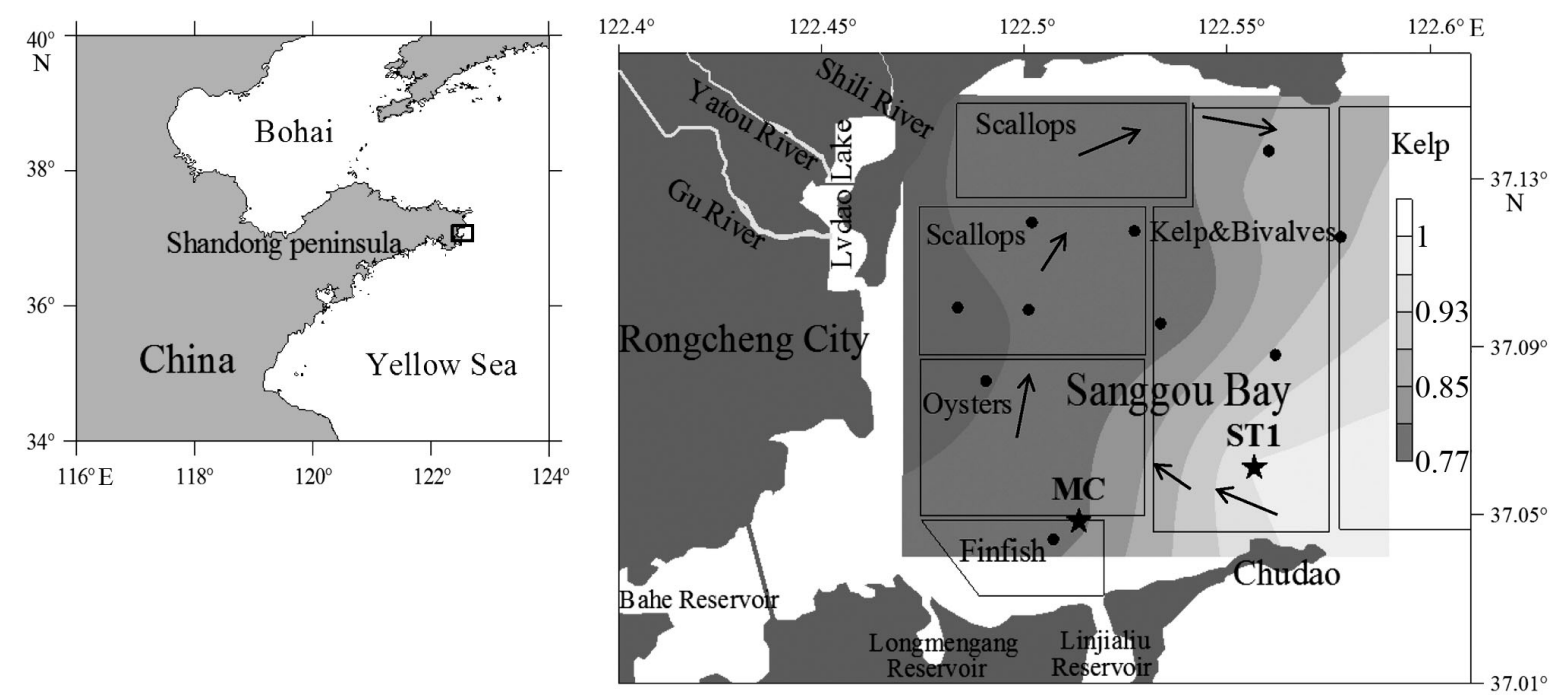

Fig. 2. Aquaculture areas (rectangles, cultured organisms indicated) and study sites in Sanggou Bay, China. $\star$ : stations used for core incubation; $\bullet$ : stations used for surface sediment sampling. Contours indicate dissolved oxygen saturation levels in bottom seawater in September 2012. Arrows represent current direction at one time of the tidal cycle modified from Bacher et al. (2003) 
tion 2012). In an IMTA system (Fig. 1) the bivalves filter suspended particulate matter, including the feces of finfish and phytoplankton; kelp assimilates nutrients from metabolic byproducts generated by the bivalves and finfish, and provides dissolved oxygen (DO) to finfish and bivalves; benthic animals are able to utilize phytoplankton and sedimentary organic detritus from aquaculture occurring in the water column, facilitating maximum nutrient recovery efficiency (Tang \& Fang 2012, Chopin, 2013). The sediments are predominantly composed of clayey silt (Zhang et al. 2006).

\section{Seawater and sediment sampling}

Field observations were carried out in Sanggou Bay in 2012, 1-2 June and 24-27 September. Surface sediments for analysis of total organic carbon (TOC) and porosity were collected from 12 stations (Fig. 2), and 2 stations located in different aquaculture conditions (polyculture vs. fish culture) were chosen for pore water extraction and core incubation to investigate benthic nutrient fluxes. Diffusion fluxes were derived from the nutrient profiles in original (i.e. at sampling of cores and before incubation) pore water obtained in the field; incubation fluxes were directly measured from core incubation, and sedimentary mineralization processes were evaluated based on nutrient data in pore water before and after incubation.

At each station, bottom seawater was collected using a Plexiglas sampler; sediments were collected using a box-sampler; 2 sediment cores were obtained with Plexiglas tubes (i.d. $=7 \mathrm{~cm}$ ) and sectioned at 1 or $2 \mathrm{~cm}$ intervals within $0.5 \mathrm{~h}$. The resulting sediment sections from one core were put into plastic bag and then frozen at $-20^{\circ} \mathrm{C}$ for later analysis, and sections from the other core were used for pore water extraction (i.e. original pore water). Pore water was extracted and filtered with Rhizon soil moisture samplers (19.21.23F Rhizon CSS) to vacuum tubes (Song et al. 2013) and then frozen at $-20^{\circ} \mathrm{C}$.

\section{Core incubation}

Each core (i.d. $=5 \mathrm{~cm}$ ) was sealed with a gas-tight lid attached and was pre-incubated in the dark at room temperature $\left(21^{\circ} \mathrm{C}\right.$ in June and $24^{\circ} \mathrm{C}$ in September 2012) for 8-12 $\mathrm{h}$ in the presence of bottom water recirculated using a peristaltic pump (Song et al. 2015). During the following incubation period the seawater was mixed using a magnetic stirrer turning a Teflon-coated magnetic stir bar at $60 \mathrm{rpm}$. At each sampling time, seawater from triplicate cores was sampled for measurement of DO and nutrients, and a sample was taken from the black bucket as a blank. Seawater for nutrient analysis was filtered with a $0.45 \mu \mathrm{m}$ pore-size syringe filter (Song et al. 2013), and the filtrate was frozen at $-20^{\circ} \mathrm{C}$. At the first and last sampling time of incubation, sediment cores were sectioned at $2 \mathrm{~cm}$ intervals for pore water extraction (i.e. pore water before and after incubation).

\section{Physical and chemical analysis}

Each frozen sediment sample was freeze dried (ALPHA 1-4 LD plus freeze dryer; Martin Christ). The water content of the sediment was calculated by determining the weight difference before and after freeze-drying (Song et al. 2013), and porosity was calculated with Berner's equation (Berner 1971). The total organic carbon (TOC) content of sediment was determined using a CHNOS Elemental Analyzer (Vario EL III, Elemental Analyzer) following removal of the carbonate fraction via reaction with $4 \mathrm{~mol} \mathrm{l}^{-1} \mathrm{HCl}_{\text {; }}$ this procedure had a precision $<6 \%$ CV (Liu et al. 2010).

Temperature and salinity were measured by a multi-parameter instrument (Multi 350i/SET, WTW $\mathrm{GmbH})$. DO concentration in seawater was measured using the Winkler titration method with a precision better than $0.5 \%$ CV (Song et al. 2015). Nutrient concentrations were determined using an autoanalyzer (AutoAnalyzer 3, SEAL Analytical). The measurement precisions for the $\mathrm{NO}_{3}{ }^{-}, \mathrm{NO}_{2}{ }^{-}, \mathrm{NH}_{4}{ }^{+}, \mathrm{PO}_{4}{ }^{3-}$, $\mathrm{Si}(\mathrm{OH})_{4}$, total dissolved nitrogen (TDN) and total dissolved phosphorus (TDP) analyses were 1, 1, 2, 1, 0.2, 3 and $5 \% \mathrm{CV}$, respectively. Dissolved organic phosphorus (DOP) concentration was calculated as TDP concentration minus $\mathrm{PO}_{4}{ }^{3-}$ concentration, and dissolved organic nitrogen (DON) concentration was calculated as TDN concentration minus dissolved inorganic nitrogen (DIN; sum of the $\mathrm{NO}_{3}{ }^{-}, \mathrm{NO}_{2}{ }^{-}$and $\mathrm{NH}_{4}{ }^{+}$) concentration.

\section{Flux calculations and statistical analysis}

Diffusion fluxes were derived from the nutrient profiles in pore water using Fick's first law of diffusion (Berner 1980, Liu et al. 2003):

$$
F=-\phi D_{\mathrm{s}}(\partial \mathrm{C} / \partial \mathrm{x})
$$

where $F$ is the diffusion flux in $m m o l \mathrm{~m}^{-2} \mathrm{~d}^{-1}, \phi$ is the porosity of the surface sediment, $D_{\mathrm{s}}$ is the whole 
Table 1. Biogeochemical properties of the bottom seawater and the sediment at Stns MC and ST1, during June and September 2012. TOC: total organic carbon; S: salinity; DO: dissolved oxygen; DON: dissolved organic nitrogen; DOP: dissolved organic phosphorus

\begin{tabular}{|c|c|c|c|c|c|c|c|c|c|c|c|c|c|}
\hline \multirow[t]{2}{*}{ Date } & \multirow[t]{2}{*}{ Stn } & \multirow{2}{*}{$\begin{array}{l}\text { Water } \\
\text { depth } \\
(\mathrm{m})\end{array}$} & \multirow{2}{*}{$\begin{array}{l}\text { Porosity } \\
\text { in } \\
\text { sediment }\end{array}$} & \multirow{2}{*}{$\begin{array}{l}\text { TOC (\%) } \\
\text { in } \\
\text { sediment }\end{array}$} & \multicolumn{9}{|c|}{ - Bottom seawater } \\
\hline & & & & & $\begin{array}{l}\text { Temp. } \\
\left({ }^{\circ} \mathrm{C}\right)\end{array}$ & $\mathrm{S}$ & $\begin{array}{c}\text { DO satura- } \\
\text { tion }(\%)\end{array}$ & $\begin{array}{l}\mathrm{NH}_{4}^{+} \\
(\mu \mathrm{M})\end{array}$ & $\begin{array}{l}\mathrm{NO}_{\mathrm{x}}^{-} \\
(\mu \mathrm{M})\end{array}$ & $\begin{array}{l}\text { DON } \\
(\mu \mathrm{M})\end{array}$ & $\begin{array}{l}\mathrm{PO}_{4}{ }^{3-} \\
(\mu \mathrm{M})\end{array}$ & $\begin{array}{l}\text { DOP } \\
(\mu M)\end{array}$ & $\begin{array}{c}\mathrm{Si}(\mathrm{OH})_{4} \\
(\mu \mathrm{M})\end{array}$ \\
\hline Jun 1 & $\mathrm{MC}$ & 9.2 & 0.70 & 0.35 & 17.7 & 31.1 & 96.5 & 1.50 & 0.19 & 12.76 & 0.08 & 0.21 & 3.87 \\
\hline Jun 2 & ST1 & 13.8 & 0.72 & 0.40 & 13.8 & 31.1 & 97.4 & 3.23 & 1.09 & 21.38 & 0.27 & 0.25 & 3.49 \\
\hline Sep 24 & $\mathrm{MC}$ & 7.8 & 0.84 & 0.68 & 25.0 & 30.0 & 79.2 & 4.14 & 5.73 & 28.83 & 1.19 & 0.21 & 24.45 \\
\hline Sep 27 & ST1 & 11.0 & 0.80 & 0.62 & 23.9 & 29.9 & 97.5 & 5.04 & 5.49 & 29.59 & 0.72 & 0.26 & 16.31 \\
\hline
\end{tabular}

sediment diffusion coefficient and $\partial C / \partial x$ is the concentration gradient close to sediment-water interface.

Incubation fluxes, which are a direct measure of net solute fluxes across the sediment-water interface, were calculated from the slope of concentrations versus time (Song et al. 2015).

Standard deviation of the linear rate was derived from the slope standard deviation given by the regression statistic; Pearson correlation was applied to discuss the correlation analysis. Statistical significance was judged using the criterion $\mathrm{p}<0.05$. Incubation fluxes were corrected to the in situ temperature using the Arrhenius equation (Aller et al. 1985, Song et al. 2015). In the present study, a positive flux (efflux) value represents a flux into the overlying water from the sediment, and a negative flux (influx) value represents a flux into the sediment from the overlying water.

\section{RESULTS}

\section{Sediment and bottom seawater parameters}

The TOC in surface sediments at both stations in September were approximately twice the level measured in June; porosities had a similar trend to that of TOC and were higher in September than in June but the values were similar at the different stations (Table 1). The bottom seawater temperature in September was higher than in June and was lower at Stn ST1 than at Stn MC because the water was depth greater at the former station. The salinity at both stations in September was slightly lower than in June. The nutrient concentrations in September were higher than in June. The DO concentrations showed saturated conditions at both stations in June, whereas in September the bottom seawater DO concentration was below saturation in the finfish and bivalve culture areas (Fig. 2).

\section{Benthic fluxes from core incubations and their stoichiometric ratios}

The DO content decreased linearly over time during incubations, and the linear slopes of the DO-time plots were similar in the various seasons (Fig. 3), although the TOC content was greater in September than in June. However, the higher in situ temperature in September resulted in greater DO influxes than in June (Fig. 4). The DO influx at Stn MC was higher than at Stn ST1 in June but was lower at Stn MC than at Stn ST1 in September.

In June, nutrients were released from the sediment to the seawater (the exception was $\mathrm{PO}_{4}{ }^{3-}$, which was transferred from seawater into the sediment), and the magnitudes of benthic nutrient flux at 2 stations were similar (Fig. 5). In September: $\mathrm{NH}_{4}{ }^{+}$was largely released at Stn $\mathrm{MC}$, but no $\mathrm{NH}_{4}{ }^{+}$flux was detected at Stn ST1 (Fig. 5a); $\mathrm{NO}_{3}{ }^{-}$was largely released at Stn ST1 but was transferred to sediment at Stn MC; $\mathrm{NO}_{2}{ }^{-}$was transferred to sediment at Stn ST1 but was released at Stn $\mathrm{MC}_{i}$ DON and TDN were transferred to sediment at both stations (Fig. 5b); $\mathrm{PO}_{4}{ }^{3-}$ was transferred to the sediment at both stations, particularly at $\mathrm{Stn} \mathrm{MC}_{\text {; }} \mathrm{DOP}$ was strongly released at Stn $\mathrm{MC}$, while DOP and TDP were transferred to sediments at Stn ST1 (Fig. 5c), and the $\mathrm{Si}(\mathrm{OH})_{4}$ efflux was less at Stn MC than at Stn ST1 and was lower in September than in June (Fig. 5d). The $\mathrm{O}_{2}$ :DIN flux ratio was higher in September than in June, and the DIN: $\mathrm{PO}_{4}{ }^{3-}$ flux ratio was lower in September than in June, while the $\mathrm{Si}(\mathrm{OH})_{4}$ :DIN flux ratio was higher in September than in June at Stn ST1 but was lower in September than in June at Stn MC (Table 2).

\section{Diffusion fluxes and nutrient profiles in pore water}

The concentrations of $\mathrm{NH}_{4}{ }^{+}, \mathrm{NO}_{\mathrm{x}}^{-}\left(\mathrm{NO}_{2}^{-}+\mathrm{NO}_{3}^{-}\right)$, $\mathrm{PO}_{4}{ }^{3-}$ and $\mathrm{Si}(\mathrm{OH})_{4}$ in pore water were measured 
Fig. 3. Time course of dissolved oxygen (DO) concentration during incubation at room temperature at Stns MC and ST1 in June and September 2012. O: DO concentration in the control bucket; : DO concentration in the water overlying the sediment
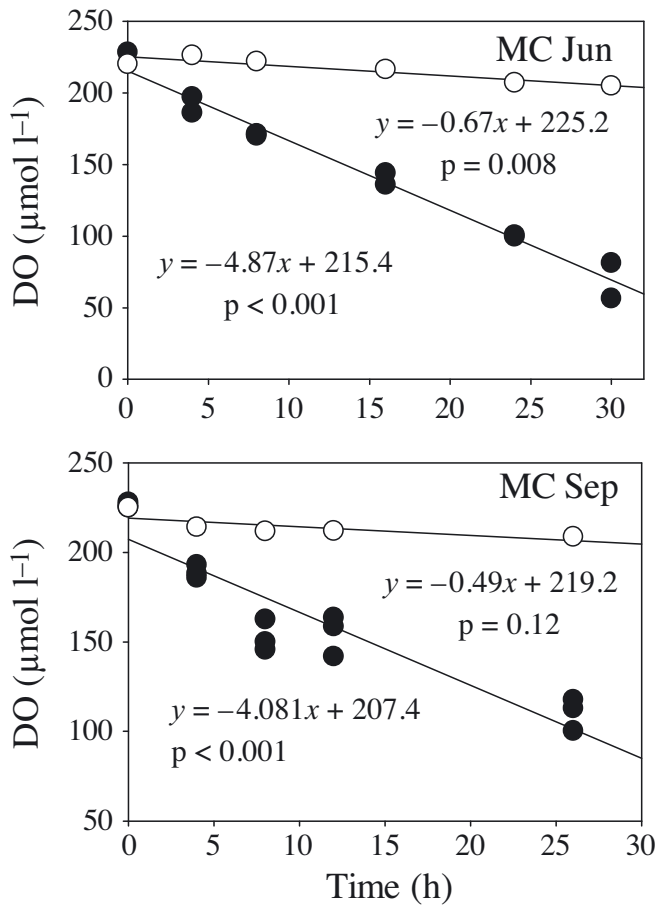
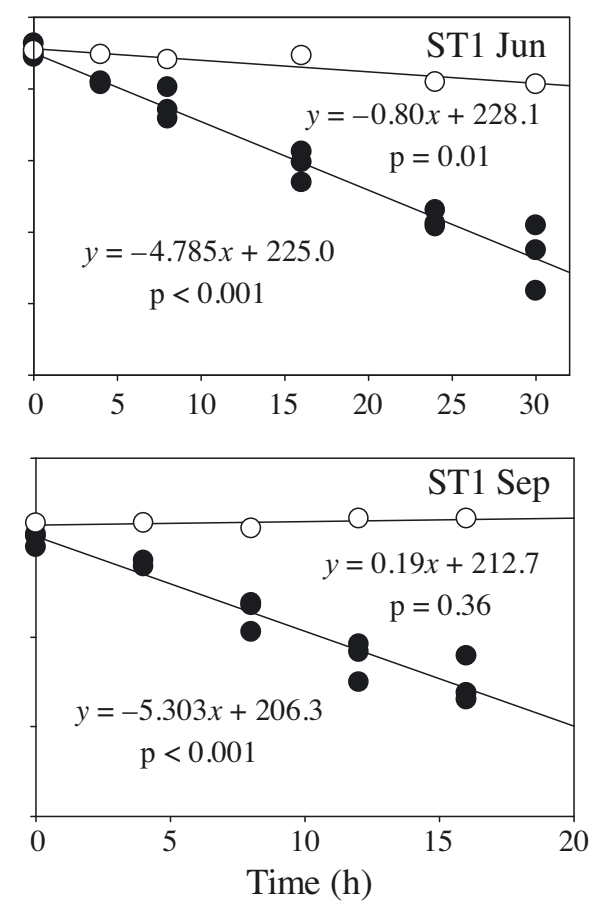

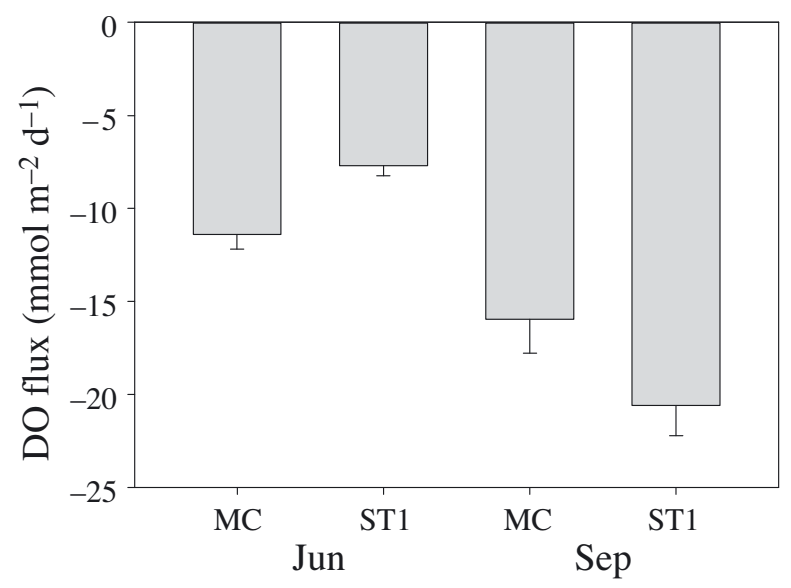

Fig. 4. Temperature-calibrated incubation fluxes of dissolved oxygen (DO) at Stns MC and ST1, during June and September 2012. Error bars show SD

when the core sediments were sampled (original) and before and after incubation (Fig. 6). The nutrient concentrations generally increased with sediment depth; the exception was the $\mathrm{NO}_{\mathrm{x}}{ }^{-}$concentration. The nutrient diffusion effluxes were supposed to be greater in September than in June as porosities of sediment were higher in September than in June, but the result was opposite. The average diffusion fluxes of DO, $\mathrm{NH}_{4}{ }^{+}, \mathrm{NO}_{\mathrm{x}}{ }^{-}, \mathrm{PO}_{4}{ }^{3-}$ and $\mathrm{Si}(\mathrm{OH})_{4}$ were 1650,1405 , 7,14 and $932 \mu \mathrm{mol} \mathrm{m}^{-2} \mathrm{~d}^{-1}$, respectively, in June and were $6470,718,-59,4$ and $818 \mu \mathrm{mol} \mathrm{m}^{-2} \mathrm{~d}^{-1}$, respectively, in September.
The nutrient profiles of $\mathrm{NH}_{4}{ }^{+}$were substantially greater after incubation, especially at Stn $\mathrm{MC}$, but there was no difference in $\mathrm{NH}_{4}{ }^{+}$concentrations before and after incubation at Stn ST1 in September; $\mathrm{NO}_{\mathrm{x}}{ }^{-}$was depleted in deep pore water and increased in surface pore water after incubation, but in September the $\mathrm{NO}_{\mathrm{x}}{ }^{-}$in surface pore water at Stn $\mathrm{MC}$ decreased after incubation; there were minor variations in the $\mathrm{PO}_{4}{ }^{3-}$ profiles for surface pore water, but in deep pore water a significant release of $\mathrm{PO}_{4}{ }^{3-}$ was observed after incubation; the differences in $\mathrm{Si}(\mathrm{OH})_{4}$ concentration before and after incubation were less in September than in June.

\section{DISCUSSION}

\section{Environmental factors controlling benthic fluxes}

A most important use of DO flux is in the indirect estimation of the total benthic organic carbon mineralization rate $\left(\mathrm{CO}_{2}\right.$ flux $)$, which is based on the Redfield ratio; the reported ratio between DO flux and $\mathrm{CO}_{2}$ flux varies from 0.8 to 1.2 , and a $\mathrm{O}_{2}: \mathrm{C}$ ratio of 1:1 was used in the present study since this ratio has been widely used for studies involving shallow waters (Glud 2008, Song et al. 2015). The quantity and quality of organic matter, temperature, DO concentration and macrofauna abundance have been suggested to be factors controlling benthic DO fluxes 

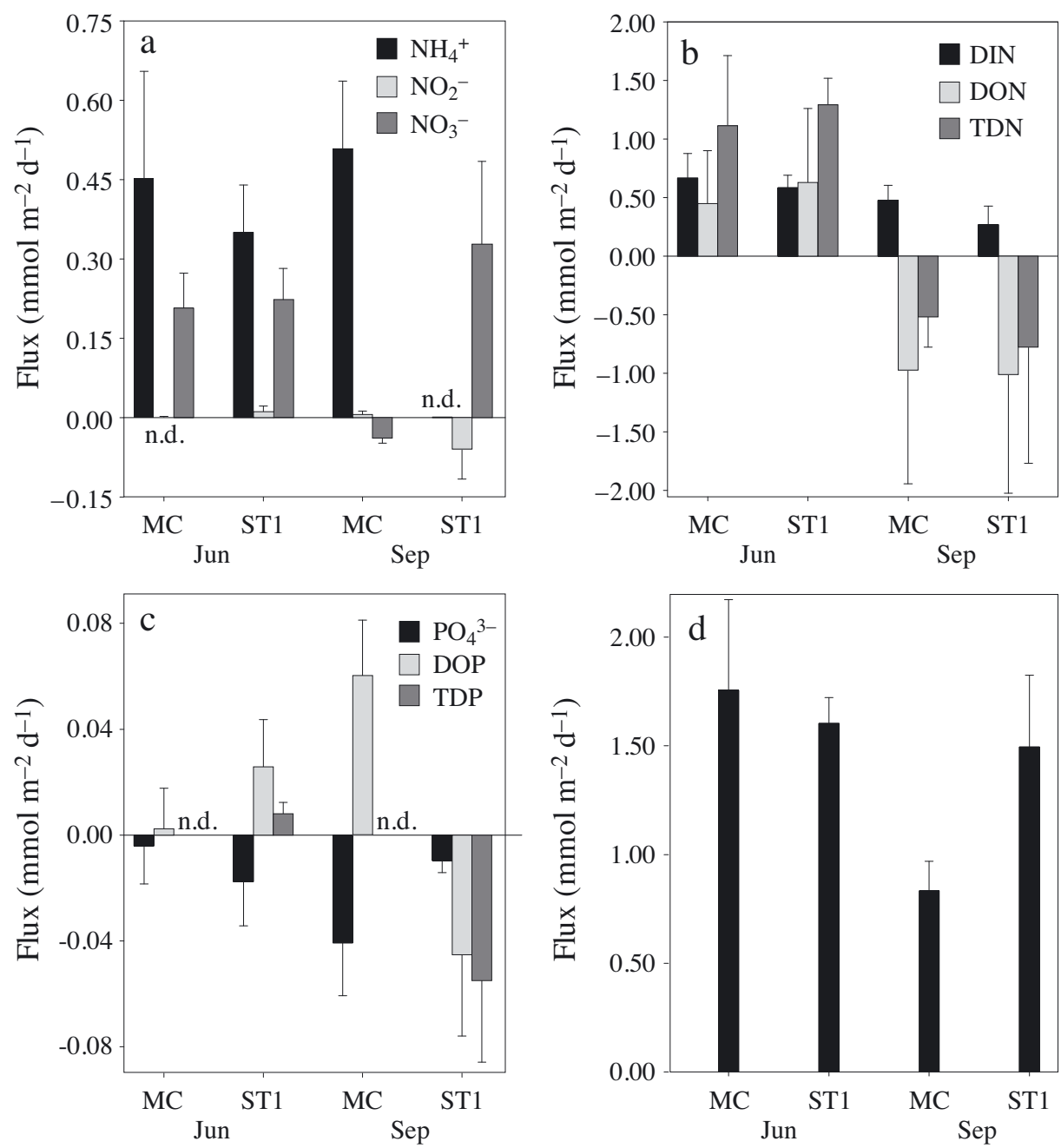

Fig. 5. Incubation fluxes of $(a, b)$ dissolved nitrogen, (c) phosphorus and (d) $\mathrm{Si}(\mathrm{OH})_{4}$ at Stns MC and ST1 in June and September 2012. Positive flux values denote fluxes into the overlying water from the sediment; negative flux values indicate fluxes into the sediment from overlying water. DIN: dissolved inorganic nitrogen; DON: dissolved organic nitrogen; TDN: total dissolved nitrogen; DOP: dissolved organic phosphorus; TDP: total dissolved phosphorus. n.d.: not detectable. Error bars show SD

(Cowan \& Boynton 1996). Benthic DO fluxes were similar under similar incubation temperatures (Fig. 3), although the TOC values were higher in September than in June. The positive correlation between calibrated DO influx $\left(F_{\mathrm{DO}}\right)$ and seawater temperature $(T)$ $\left(F_{\mathrm{DO}}=-0.99 T+0.36, \mathrm{R}^{2}=0.79\right)$ indicated that temperature rather than TOC is one factor controlling $\mathrm{CO}_{2}$ fluxes in Sanggou Bay sediment. This was consistent with another IMTA bay, i.e. Ailian Bay, China, in that the contribution rates of biodeposits by the shellfish

Table 2. Stoichiometric ratios of benthic fluxes at Stns MC and ST1, during June and September 2012. $\mathrm{PO}_{4}{ }^{3-}$ fluxes were diffusion fluxes. DIN: dissolved inorganic nitrogen

\begin{tabular}{|lcccc|}
\hline Date & Stn & $\mathrm{O}_{2}: \mathrm{DIN}$ & ${\mathrm{DIN}: \mathrm{PO}_{4}{ }^{3-}}$ & $\mathrm{Si}(\mathrm{OH})_{4}: \mathrm{DIN}$ \\
\hline Jun 1 & MC & 17 & 40 & 3 \\
Jun 2 & ST1 & 13 & 60 & 3 \\
Sep 24 & MC & 33 & 34 & 2 \\
Sep 27 & ST1 & 76 & 17 & 6 \\
\hline
\end{tabular}

and kelp to the sediments in the IMTA area were very low (Ren et al. 2014), but benthic DO fluxes were positively correlated to TOC sedimentation in monoculture areas (Carlsson et al. 2012). Moreover, the low DO saturation level at Stn MC in September resulted in a lesser DO influx than that of Stn ST1 (Fig. 4), suggesting that DO in bottom seawater is also one factor controlling $\mathrm{CO}_{2}$ fluxes in Sanggou Bay. Benthic $\mathrm{CO}_{2}$ fluxes removed 12 and $6 \%$ of $\mathrm{C}$ input via sedimentation in June and September, respectively, but other parts of the sedimentary matter were mainly transported by horizontal fluxes including bioturbation and resuspension (Fig. 7). In Jiaozhou Bay (China) the polychaete bioturbation resulted in a $25 \%$ greater DO flux than that in the absence of bioturbation (Zhang et al. 2006). Hung et al. (2013) also reported resuspension may have contributed $27-93 \%$ of the POC flux in the East China Sea. However, the sedimentation fluxes may have been overestimated, as it is possible that their values included materials transported horizontally and re- 


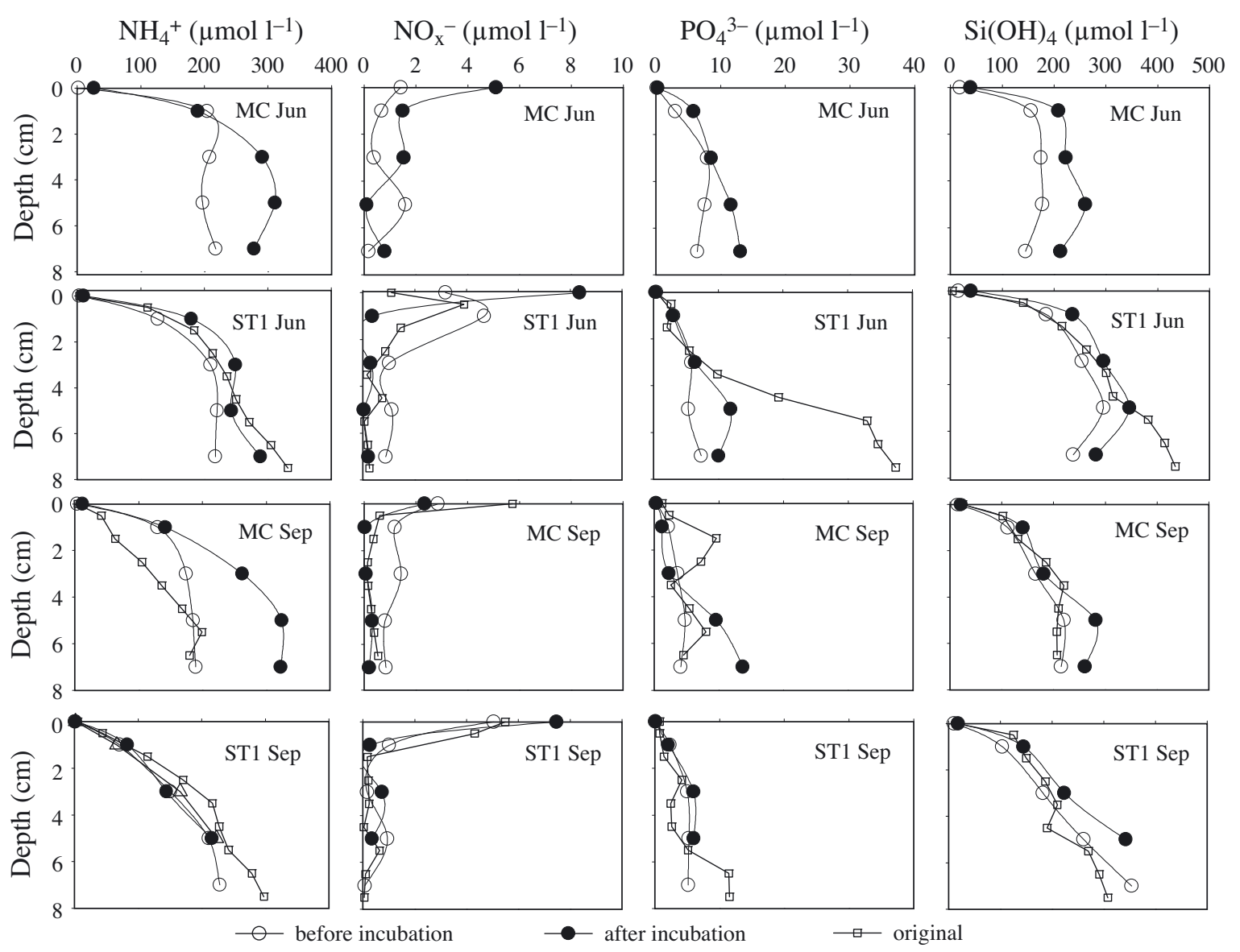

Fig. 6. Nutrient profiles in pore water when the core sediments were sampled (original) and before and after incubation. MC and ST1 are the sampling stations; sampling was done in June and September 2012. Core sediment for original pore water was not sampled at Stn MC in June

mobilized particulates (Hatcher et al. 1994); therefore, these estimated values need confirmation.

Benthic $\mathrm{N}$ fluxes are affected by the microbial activities including nitrification and denitrification (Jansen et al. 2012). The elevated $\mathrm{O}_{2}$ :DIN flux ratio (Table 2) was much higher than the Redfield ratio (i.e. 6.6), which suggests that substantial coupled nitrification-denitrification (Cowan \& Boynton 1996) occurred in September. The denitrification rate in Sanggou Bay was $0.19-0.37 \mathrm{mmol} \mathrm{m}^{-2} \mathrm{~d}^{-1}$ (Z. Ning et al. unpubl. data), but the high $\mathrm{O}_{2}$ : $\left(\mathrm{DIN}+\mathrm{N}_{2}\right)$ flux ratio (10-29) (which still exceeded the Redfield ratio) indicated that $30-77 \%$ of the mineralized $\mathrm{NH}_{4}{ }^{+}$was retained in the Sanggou Bay sediment. The porosity of the sediment should positively relate to the benthic nutrient diffusion flux (Berner 1980); nevertheless, benthic nutrient fluxes were greater in June than in September, although porosity was higher in September than in June (Fig. 7). Although grain size was not determined in this study, grain sizes at different stations should be similar, since the porosities were sim- ilar at the 2 stations (Table 1 ). Hence, neither porosity nor grain size were the main factors controlling benthic nutrient fluxes in the IMTA system.

Fluxes of $\mathrm{PO}_{4}{ }^{3-}$ depend on the $\mathrm{PO}_{4}{ }^{3-}$ production rate, the adsorption-desorption equilibrium in the sediment, and the thickness of the diffusion boundary layer at the sediment-water interface (Sundby et al. 1992). Adsorption of $\mathrm{PO}_{4}{ }^{3-}$ by $\mathrm{MnO}_{2} / \mathrm{FeOOH}$ (Woulds et al. 2009) may explain why $\mathrm{PO}_{4}{ }^{3-}$ was transferred to the sediment at both stations (Fig. 5c). Although the N loss by coupled nitrification-denitrification and $\mathrm{NH}_{4}{ }^{+}$ adsorption onto clay minerals contributed to the low DIN efflux, the high DIN: $\mathrm{PO}_{4}{ }^{3-}$ flux ratios (Table 2 ) indicated the degree to which $\mathrm{PO}_{4}{ }^{3-}$ is retained by adsorption in Sanggou Bay. Hence, $\mathrm{PO}_{4}{ }^{3-}$ sorption widely occurred in monoculture (Hyun et al. 2013) and IMTA areas. The DOP fluxes were mainly affected by aquaculture activities (see 'Aquaculture activities and benthic nutrient fluxes in different seasons').

The benthic $\mathrm{Si}(\mathrm{OH})_{4}$ fluxes in Sanggou Bay were higher than the nitrogen and phosphorus fluxes 

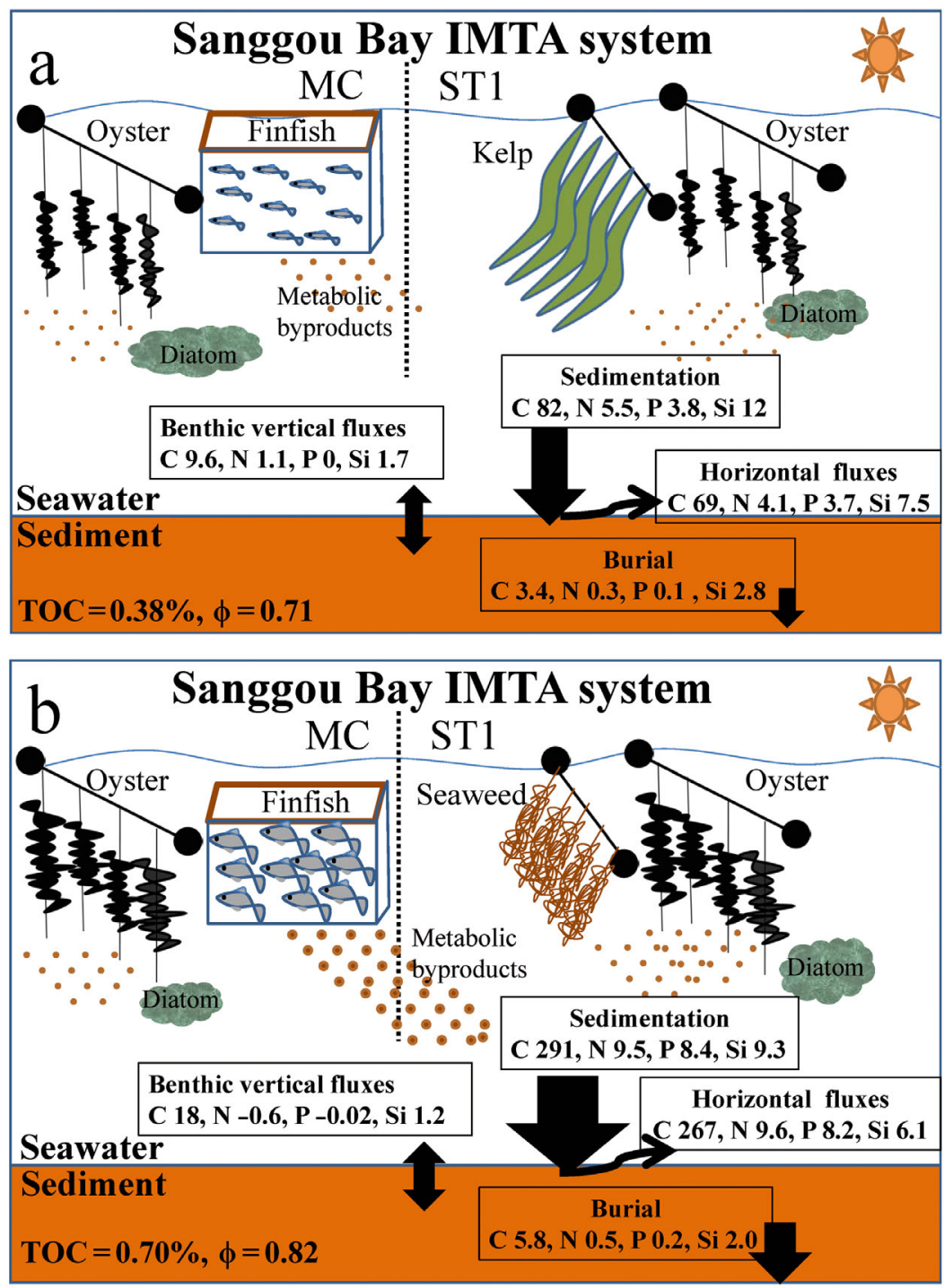

Fig. 7. Sedimentary cycles of C, N, P, Si in (a) June and (b) September 2012 in the Sanggou Bay integrated multi-trophic aquaculture (IMTA) system. Benthic vertical fluxes were measured from core incubation; $\mathrm{C}$ fluxes were calculated from the Redfield ratio using dissolved oxygen fluxes. Sedimentation fluxes measured by sediment traps were sourced from Cai et al. (2003); burial fluxes were sourced from Song et al. (2012); horizontal fluxes including resuspension and bioturbation were calculated by difference. All units of fluxes in the boxes are mmol m $\mathrm{m}^{-2} \mathrm{~d}^{-1}$. IMTA: integrated multi-trophic aquaculture; TOC: total organic carbon; $\phi$ : porosity of the surface sediment. MC and ST1 are the sampling stations

(Fig. 5). Biogenic silica reaches the sediment surface mainly in the form of skeletons or skeletal fragments of silica-secreting microorganisms (Zabel et al. 1998), and dissolution of sedimentary biogenic silica dominates the dissolved silicate content of pore water (Aller et al. 1985, Liu et al. 2003). Diatoms were predominant in the phytoplankton community in Sanggou Bay (Yuan et al. 2014). Consequently, tempera- ture and the biomass of diatoms in seawater are the main factors controlling benthic $\mathrm{Si}(\mathrm{OH})_{4}$ fluxes. The seawater temperature was higher in September than in June, and therefore the $\mathrm{Si}(\mathrm{OH})_{4}$ fluxes were expected to be higher in September but were found to be higher in June (Fig. 5d). The higher $\mathrm{Si}(\mathrm{OH})_{4}$ concentration in seawater in September (Table 1) was related to a lesser biomass of diatoms in the seawater, because the abundance of phytoplankton was tightly controlled by filter-feeding oysters (Hyun et al. 2013); therefore, heavy grazing by oysters may result in the reduction of the $\mathrm{Si}(\mathrm{OH})_{4}$ flux at Stn MC in September. In comparison to other monoculture areas, competition with co-cultivated kelp resulted in lower diatom biomass in the IMTA system (Yuan et al. 2014), resulting in lower benthic $\mathrm{Si}(\mathrm{OH})_{4}$ fluxes in the IMTA than in monoculture (Table 3).

\section{Aquaculture activities and benthic nutrient fluxes in different seasons}

In June the concentrations of nutrients in seawater were quite low because the kelp Saccharina japonica assimilated substantial nutrients in spring (Shi et al. 2011), and the metabolic byproducts of finfish and oysters in the early growth stages produced low levels of nutrients in seawater (Fig. 7a). In September the seaweed Gracilaria lemaneiformis replaced kelp, and finfish and oysters were in active growth stages and generated large quantities of metabolic byproducts (Fig. 7b). The maximum metabolic rates from Pacific oyster were recorded in July and August (Mao et al. 2006), and decomposition resulted in high nutrient concentrations in the seawater. In addition to assimilation by kelp, $\mathrm{Si}(\mathrm{OH})_{4}$ concentration was tightly related to the biomass of diatoms, as diatoms were predominant in the phytoplankton community in Sanggou Bay (Yuan et al. 2014). Hence, ratios of $\mathrm{Si}(\mathrm{OH})_{4}$ :DIN concentrations were higher in September than in June, especially at Stn MC due to heavy grazing by oysters 
(Hyun et al. 2013). When discussing the impacts of aquaculture on benthic nutrient fluxes, it is important to clarify the sources of brodeposits by the marine organisms to the sediments using sediment traps or natural isotopic tracers, etc. However, TOC was not a directly controlling factor of benthic fluxes in an IMTA system as discussed in 'Environmental factors controlling benthic fluxes'; therefore, the sources of biodeposits by the marine organims to the sediment were not an object of this study.

In June, the decrease in nutrient concentrations in seawater enlarges the concentration gradient in the sediment-water interface, which may result in larger diffusion effluxes (Berner 1980). Hence, all nutrients are released from the sediments to the seawater except $\mathrm{PO}_{4}{ }^{3-}$, and the effluxes in June were greater than in September (Fig. 5). The benthic effluxes of DIN and $\mathrm{Si}(\mathrm{OH})_{4}$ contributed 4 and $11 \%$, respectively, of gross primary productivity (GPP) (including the GPP of kelp). DON can be assimilated by seagrass and macroalgae (Vonk et al. 2008). Assuming DIN and DON released from the sediment was completely consumed by phytoplankton and kelp, the benthic TDN efflux contributed $8 \%$ of GPP. The benthic nutrient contributions to GPP were much smaller than that in the Mandovi Estuary (Pratihary et al. 2009), on the west coast of Sweden (Sundbäck et al. 2003) and in Jinhae Bay (Lee et al. 2011), since substantial cultivation of kelp made the highest contribution to GPP in the IMTA system. If only the GPP of kelp is taken into account, the benthic effluxes of DIN and $\mathrm{Si}(\mathrm{OH})_{4}$ contributed 7 and $18 \%$ of algal $\mathrm{N}$ and Si demands. The low contribution of benthic mineralization may be due to efficient recycling of organic matter in the IMTA system, which will be discussed in 'Benthic nutrient fluxes in different aquaculture modes'. The fact that benthic $\mathrm{PO}_{4}{ }^{3--}$ fluxes made no contribution to GPP in Sanggou Bay is consistent with the finding of Hatcher et al. (1994) that suspended mussel culture had little impact on sediment phosphorus dynamics in Upper South Cove (Nova Scotia, Canada). The sedimentation flux of carbon was $82 \mathrm{mmol} \mathrm{m}^{-2} \mathrm{~d}^{-1}$ in June (Cai et al. 2003), which was much lower than that in September, and therefore the TOC in sediment remained at a low level $(0.30 \%)$. With respect to nutrient feedback in pore water (Fig. 6), large amounts of DIN and $\mathrm{Si}(\mathrm{OH})_{4}$ were generated after incubation, suggesting large potential DIN and $\mathrm{Si}(\mathrm{OH})_{4}$ effluxes, while the generated $\mathrm{PO}_{4}{ }^{3-}$ was not released to the seawater; the decrease in surface $\mathrm{PO}_{4}{ }^{3-}$ after incubation was probably caused by adsorption by $\mathrm{Mn} / \mathrm{Fe}$ oxides (Woulds et al. 2009). However, this was offset by the release of DOP.

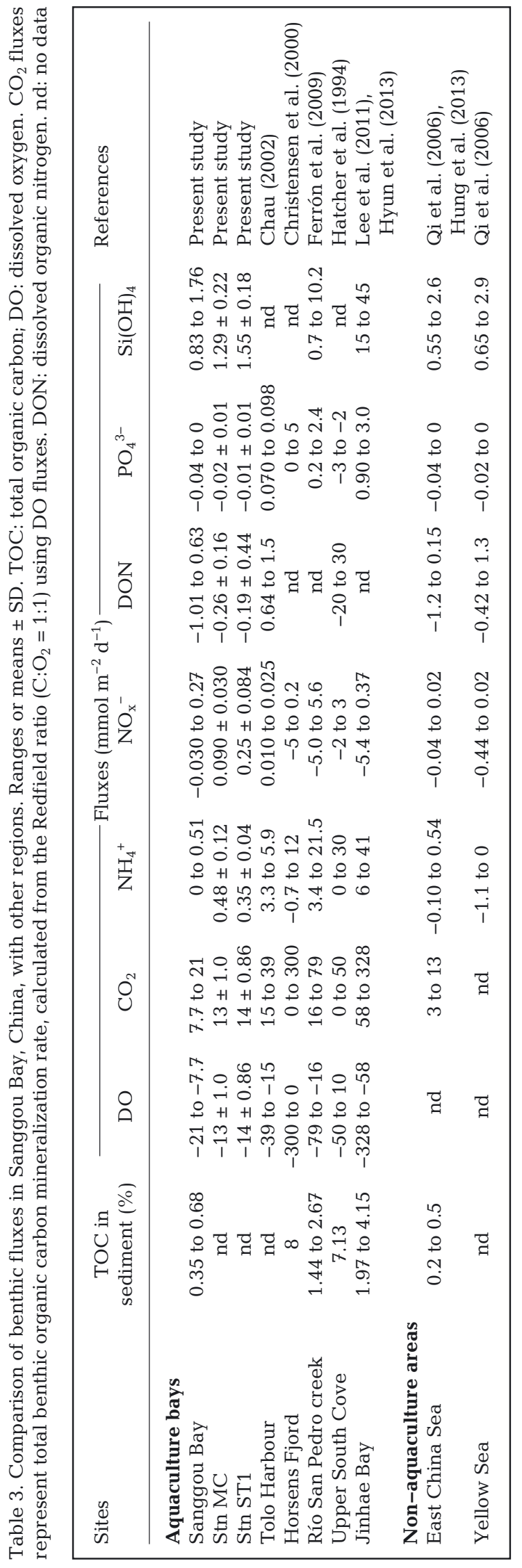


In September, an intense biodeposition resulted in high levels of TOC accumulation in sediment and high DO and DON influxes (Hatcher et al. 1994). Based on the metabolic rates of $\mathrm{NH}_{4}{ }^{+}(57 \mathrm{t} \mathrm{N})$ and $\mathrm{PO}_{4}{ }^{3-}$ (11 t P) from the Pacific oyster (Mao et al. 2006) and benthic influxes of TDN and TDP in September, sediment may be able to take up $64 \%$ of the $\mathrm{N}$ and $25 \%$ of the $\mathrm{P}$ metabolized by oysters. With respect to nutrient feedback in pore water (Fig. 6), at Stn MC the $\mathrm{NH}_{4}{ }^{+}$level in pore water was significantly increased and the $\mathrm{NO}_{\mathrm{x}}{ }^{-}$was depleted after incubation, which is consistent with high levels of $\mathrm{NH}_{4}{ }^{+}$efflux and $\mathrm{NO}_{\mathrm{x}}{ }^{-}$influx at high biodeposition sites (Gilbert et al. 1997, Christensen et al. 2000). When $\mathrm{NO}_{\mathrm{x}}{ }^{-}$is depleted, $\mathrm{MnO}_{2} / \mathrm{FeOOH}$ were reduced and the adsorption of $\mathrm{PO}_{4}{ }^{3-}$ substantially decreased, which explains why a marked increase in the $\mathrm{PO}_{4}{ }^{3-}$ concentration was observed in deep pore water after incubation at Stn MC. At Stn ST1 there was no obvious increase in the $\mathrm{NH}_{4}{ }^{+}$concentration in pore water after incubation, probably because of the removal of $\mathrm{N}$ by coupled nitrification-denitrification or adsorption (discussed in 'Environmental factors controlling benthic fluxes').

\section{Benthic nutrient fluxes in different aquaculture modes}

Increased biodeposits produced by the actively growing animals can result in a substantial increase in the organic content of sediment (Hatcher et al. 1994, Christensen et al. 2000, Ferrón et al. 2009, Lee et al. the benthic effluxes in Sanggou Bay were significantly less than in other monoculture areas. During the polyculture period, the annual gross yield of seafood increased especially in the 2000 s, and the proportion of different species changed continuously so that the optimal aquatic environment was obtained (Zhang et al. 2009). Once the IMTA was widely implemented in Sanggou Bay, the DIN concentration dropped to a moderate level; the TOC of sediment and the benthic effluxes in Sanggou Bay are comparable with that in non-aquaculture areas such as the East China Sea (Table 3), though substantial aquaculture activities have been implemented in Sanggou Bay.

In Sanggou Bay, the benthic mineralization rates $\left(\mathrm{CO}_{2}\right.$ fluxes $)$ at the 2 different stations were similar, but the benthic nutrient fluxes were different, which reflected the impacts of different aquaculture modes (Table 3). In September, DO was at near saturation levels at Stn ST1 (polyculture area of kelp and oyster) but below saturation at Stn MC (the fish culture area, and near the oyster area) (Fig. 2; contours of DO saturation); the lower DO level at Stn MC led to an increase in the $\mathrm{NH}_{4}{ }^{+}$efflux and a decrease in the $\mathrm{NO}_{\mathrm{x}}{ }^{-}$efflux. Hyun et al. (2013) reported DO concentrations less than saturation in bottom waters at an oyster farm, presumably because of the combination of DO consumption at the sediment-water interface and the dense suspended culture that limits seawater exchange and the replenishment of DO. Conversely, at Stn ST1, DO provided by kelp helps to maintain the DO saturation level. Hence, greater $\mathrm{NO}_{\mathrm{x}}{ }^{-}$efflux was observed at Stn ST1 than at Stn MC. The influxes of DON and $\mathrm{PO}_{4}{ }^{3-}$ were higher at Stn $\mathrm{MC}$ 2011); the mineralization of sedimentation can release substantial nutrients from the sediment to the seawater, which may result in the deterioration of seawater quality (Chau 2002). Hence, the TOC in the sediment and benthic effluxes of nutrients in traditional aquaculture areas were extremely high (Table 3). Monoculture was implemented in Sanggou Bay in the 1970s; the extremely high TOC in the sediment and the low DIN concentration in the seawater may have resulted in great benthic nutrient fluxes in this monoculture period (Fig. 8). Since 1980 the introduction of polyculture in Sanggou Bay has resulted in the reduction of TOC in the sediment (Song et al. 2012). And the high DIN concentration in the seawater indicated that substantial organic matter was recycling in the seawater during the polyculture period. The efficient recycling of organic matter and nutrients explains why the TOC of sediment and

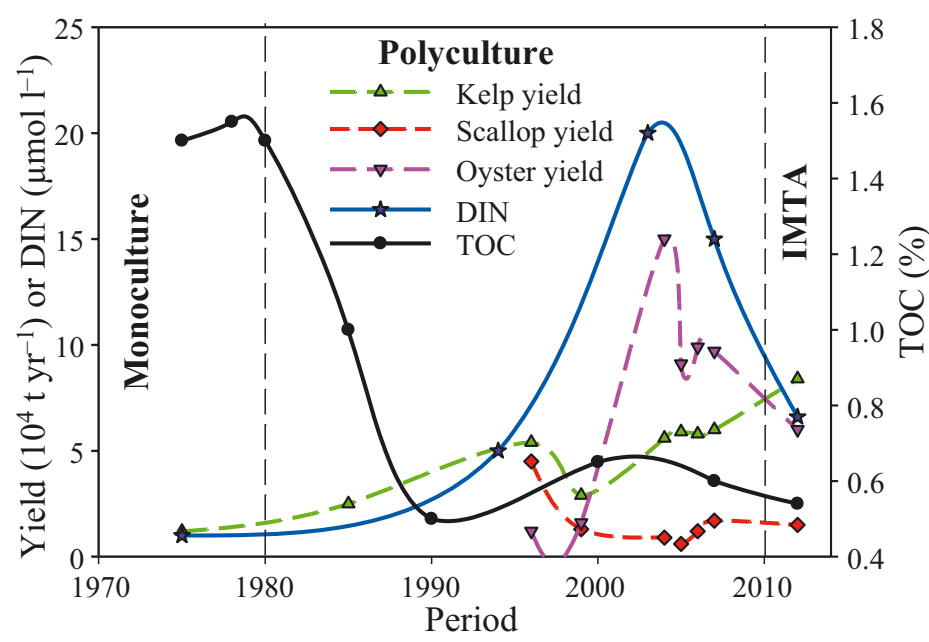

Fig. 8. Historical data of yield, dissolved inorganic nitrogen (DIN) concentration in seawater and total organic carbon (TOC) in sediment, which were sourced from Zhang et al. (2009), Li et al. (2016, this Theme Section) and Song et al. (2012), respectively. IMTA: integrated multi-trophic aquaculture 
than at Stn ST1, probably due to the greater metabolic rates from bivalves in the oyster culture area than in the polyculture area of kelp and oyster (Cai et al. 2003). More filtration of diatoms by bivalves in the oyster culture than in the kelp and oyster polyculture area may explain why $\mathrm{Si}(\mathrm{OH})_{4}$ efflux at $\mathrm{Stn} \mathrm{MC}$ was lower than at Stn ST1.

In summary, the benthic nutrient fluxes were significantly lower in the IMTA system than in other monoculture areas and were impacted by DO levels at different culture stations rather than by sedimentary TOC generated from aquaculture species. Seasonal variations in benthic fluxes were controlled by temperature and nutrient concentrations related to aquaculture.

Acknowledgements. This study was supported financially by the Ministry of Science \& Technology of China (2011 CB409802) and the National Science Foundation of China (40925017). Additional financial support was provided by SKLEC/ECNU for TOC determination. We sincerely thank Senlin Wang, Director of the Chudao Fisheries Corporation, for his cooperation, and thank Guodong Song, Xuming Kang, Shuhang Dong and Mingshuang Sun for their help in the field. We are grateful to the 3 anonymous reviewers and the editor for their comments.

\section{LITERATURE CITED}

Aller RC, Mackin JE, Ullman WJ, Wang CH and others (1985) Early chemical diagenesis, sediment-water solute exchange, and storage of reactive organic matter near the mouth of the Changjiang, East China Sea. Cont Shelf Res 4:227-251

Bacher C, Grant J, Hawkins AJS, Fang JG, Zhu MY, Besnard M (2003) Modelling the effect of food depletion on scallop growth in Sungo Bay (China). Aquat Living Resour 16:10-24

Berner RA (1971) Principles of chemical sedimentology. McGraw-Hill, New York, NY

Berner RA (1980) Early diagenesis: a theoretical approach. Princeton University Press, Princeton, NJ

Cai LS, Fang JG, Liang XM (2003) Natural sedimentation in large-scale aquaculture areas of Sungo Bay, north China Sea. J Fish Sci China 10:305-310 (in Chinese with English Abstract)

Carlsson MS, Engström P, Lindahl O, Ljungqvist L, Petersen JK, Svanberg L, Holmer M (2012) Effects of mussel farms on the benthic nitrogen cycle on the Swedish west coast. Aquacult Environ Interact 2:177-191

Chau KW (2002) Field measurements of SOD and sediment nutrient fluxes in a land-locked embayment in Hong Kong. Adv Environ Res 6:135-142

Chopin T (2013) Aquaculture, integrated multi-trophic (IMTA). In: Christou P, Savin R, Costa-Pierce B, Misztal I, Whitelaw B (eds) Sustainable food production. Springer, New York, NY, p 184-205

> Christensen PB, Rysgaard S, Sloth NP, Dalsgaard T, Schwærter S (2000) Sediment mineralization, nutrient fluxes, denitrification and dissimilatory nitrate reduction to ammonium in an estuarine fjord with sea cage trout farms. Aquat Microb Ecol 21:73-84

Cowan JLW, Boynton WR (1996) Sediment-water oxygen and nutrient exchanges along the longitudinal axis of Chesapeake Bay: seasonal patterns, controlling factors and ecological significance. Estuaries 19:562-580

FAO (Food and Agriculture Organization of the United Nations) (2012) The state of world fisheries and aquaculture. FAO, Rome

> Ferrón S, Ortega T, Forja JM (2009) Benthic fluxes in a tidal salt marsh creek affected by fish farm activities: Río San Pedro (Bay of Cádiz, SW Spain). Mar Chem 113:50-62

Gilbert F, Souchu P, Bianchi M, Bonin P (1997) Influence of shellfish farming activities on nitrification, nitrate reduction to ammonium and denitrification at the watersediment interface of the Thau lagoon, France. Mar Ecol Prog Ser 151:143-153

> Glud RN (2008) Oxygen dynamics of marine sediments. Mar Biol Res 4:243-289

> Hatcher A, Grant J, Schofield B (1994) Effects of suspended mussel culture (Mytilus spp.) on sedimentation, benthic respiration and sediment nutrient dynamics in a coastal bay. Mar Ecol Prog Ser 115:219-235

Hung CC, Tseng CW, Gong GC, Chen KS, Chen MH, Hsu SC (2013) Fluxes of particulate organic carbon in the East China Sea in summer. Biogeosciences 10:6469-6484

Hyun JH, Kim YT, Mok JS, Lee JS, An SU, Lee WC, Jung RH (2013) Impacts of long-line aquaculture of Pacific oysters (Crassostrea gigas) on sulfate reduction and diffusive nutrient flux in the coastal sediments of JinhaeTongyeong, Korea. Mar Pollut Bull 74:187-198

Jansen HM, Verdegem MCJ, Strand Ø, Smaal AC (2012) Seasonal variation in mineralization rates (C-N-P-Si) of mussel Mytilus edulis biodeposits. Mar Biol 159:1567-1580

> Lee JS, Kim YT, Shin KH, Hyun JH, Kim SY (2011) Benthic nutrient fluxes at longline sea squirt and oyster aquaculture farms and their role in coastal ecosystems. Aquacult Int 19:931-944

Li R, Liu S, Zhang J, Jiang Z, Fang J (2016) Sources and export of nutrients associated with integrated multi-trophic aquaculture in Sanggou Bay, China. Aquacult Environ Interact 8:285-309

> Liu SM, Zhang J, Jiang WS (2003) Pore water nutrient regeneration in shallow coastal Bohai Sea, China. J Oceanogr 59:377-385

Liu SM, Zhu BD, Zhang J, Wu Y and others (2010) Environmental change in Jiaozhou Bay recorded by nutrient components in sediments. Mar Pollut Bull 60:1591-1599

Lu JC, Huang LF, Luo YR, Xiao T, Jiang ZJ, Wu LN (2015) Effects of freshwater input and mariculture (bivalves and macroalgae) on spatial distribution of nanoflagellates in Sungo Bay, China. Aquacult Environ Interact 6:191-203

> Mao YZ, Zhou Y, Yang HS, Wang RC (2006) Seasonal variation in metabolism of cultured Pacific oyster, Crassostrea gigas, in Sanggou Bay, China. Aquaculture 253:322-333

Nunes JP, Ferreira JG, Gazeau F, Lencart-Silva J, Zhang XL, Zhu MY, Fang JG (2003) A model for sustainable management of shellfish polyculture in coastal bays. Aquaculture 219:257-277

> Pratihary AK, Naqvi SWA, Naik H, Thorat BR, Narvenkar G, Manjunatha BR, Rao VP (2009) Benthic fluxes in a tropical estuary and their role in the ecosystem. Estuar Coast Shelf Sci 85:387-398

Qi XH, Liu SM, Zhang J (2006) Sediment-water fluxes of nutrients in the Yellow Sea and the East China Sea. Mark 
Sci 30:9-15 (in Chinese with English Abstract)

Ren L, Zhang J, Fang J, Tang Q, Zhang M, Du M (2014) Impact of shellfish biodeposits and rotten seaweed on the sediments of Ailian Bay, China. Aquacult Int 22:811-819

Sequeira A, Ferreira JG, Hawkins AJS, Nobre A and others (2008) Trade-offs between shellfish aquaculture and benthic biodiversity: a modelling approach for sustainable management. Aquaculture 274:313-328

Shi J, Wei H, Zhao L, Yuan Y, Fang JG, Zhang JH (2011) A physical-biological coupled aquaculture model for a suspended aquaculture area of China. Aquaculture 318: 412-424

Song XL, Yang Q, Sun Y, Yin H, Jiang SL (2012) Study of sedimentary section records of organic matter in Sanggou Bay over the last 200 years. Acta Oceanol Sin 34: 120-126 (in Chinese with English Abstract)

Song GD, Liu SM, Marchant H, Kuypers MMM, Lavik G (2013) Anammox, denitrification and dissimilatory nitrate reduction to ammonium in the East China Sea sediment. Biogeosciences 10:6851-6864

Song GD, Liu SM, Zhu ZY, Zhai WD, Zhu CJ, Zhang J (2015) Sediment oxygen consumption and benthic organic carbon mineralization on the continental shelves of the East China Sea and the Yellow Sea. Deep-Sea Res II, doi: 10.1016/j.dsr2.2015.04.012

Sundbäck K, Miles A, Hulth S, Pihl L, Engström P, Selander E, Svenson A (2003) Importance of benthic nutrient regeneration during initiation of macroalgal blooms in shallow bays. Mar Ecol Prog Ser 246:115-126

Sundby B, Gobeil C, Silverberg N, Mucci A (1992) The phosphorus cycle in coastal marine sediments. Limnol Oceanogr 37:1129-1145

Tang QS, Fang JG (2012) Review of climate change effects

Editorial responsibility: Simone Mirto (Guest Editor), Castellammare del Golfo, Italy in the Yellow Sea large marine ecosystem and adaptive actions in ecosystem based management. In: Sherman K, McGovern G (eds) Frontline observations on climate change and sustainability of large marine ecosystems. UNDP, New York, NY, p 170-187

Troell M, Joyce A, Chopin T, Neori A, Buschmann AH, Fang JG (2009) Ecological engineering in aquaculturepotential for integrated multi-trophic aquaculture (IMTA) in marine offshore systems. Aquaculture 297:1-9

Vonk JA, Middelburg JJ, Stapel J, Bouma TJ (2008) Dissolved organic nitrogen uptake by seagrasses. Limnol Oceanogr 53:542-548

Woulds C, Schwartz MC, Brand T, Cowie GL, Law G, Mowbray SR (2009) Porewater nutrient concentrations and benthic nutrient fluxes across the Pakistan margin OMZ. Deep-Sea Res II 56:333-346

> Yuan ML, Zhang CX, Jiang ZJ, Guo SJ, Sun J (2014) Seasonal variations in phytoplankton community structure in the Sanggou, Ailian, and Lidao Bays. J Ocean Univ China 13:1012-1024

Zabel M, Dahmke A, Schulz HD (1998) Regional distribution of diffusive phosphate and silicate fluxes through the sediment-water interface: the eastern South Atlantic. Deep-Sea Res I 45:277-300

Zhang XL, Zhu MY, Chen S, Grant J, Martin JLM (2006) Study on sediment oxygen consumption rate in the Sanggou Bay and Jiaozhou Bay. Adv Mar Sci 24:91-96 (in Chinese with English Abstract)

Zhang JH, Hansen PK, Fang JG, Wang W, Jiang ZJ (2009) Assessment of the local environmental impact of intensive marine shellfish and seaweed farming - application of the MOM system in Sungo Bay, China. Aquaculture 287:304-310

Submitted: May 8, 2015; Accepted: July 30, 2015

Proofs received from author(s): October 6, 2015 